\title{
Mediating Effect Of The Motivation For Medication Use On Disease Management And Medication Adherence Among Community-Dwelling Patients With Schizophrenia
}

This article was published in the following Dove Press journal:

Patient Preference and Adherence

\author{
Wen Ling Hsieh' \\ Shih Kai Lee ${ }^{2}$ \\ Wai Tong Chien (iD ${ }^{3}$ \\ Wen I Liu ${ }^{4}$ \\ Chien Yu Lai ${ }^{4}$ \\ Chieh Yu Liu iD ${ }^{4}$ \\ 'Department of Nursing, Taipei Municipal \\ Wanfang Hospital (Managed by Taipei \\ Medical University), Taipei City, Taiwan; \\ ${ }^{2}$ Department of Nursing, Tsaotun \\ Psychiatric Center, Ministry of Health and \\ Welfare, Nan-Tou, Taiwan; ${ }^{3}$ The \\ Nethersole School of Nursing, Faculty of \\ Medicine, The Chinese University of \\ Hong Kong, Hong Kong; ${ }^{4}$ College of \\ Nursing, National Taipei University of \\ Nursing and Health Sciences, Taipei City, \\ Taiwan
}

Background: Nearly half of patients with schizophrenia do not adhere to the long-term medical treatment needed to manage their disease. Programs to promote medication adherence include promotion of motivation as a critical element to influence task performance.

Purpose: This study investigated the mediating effect of motivation for medication use on disease management and medication adherence in schizophrenia.

Methods: This cross-sectional, descriptive correlational study enrolled a convenience sample of 373 community-dwelling patients with schizophrenia in the northern and central regions of Taiwan. Data were collected with questionnaires and a series of validated assessment tools. Hierarchical regression was used to analyze the mediating effect of motivation for medication use on disease management and medication adherence.

Results: The medication adherence rate of the patients was $47.2 \%$. The mediating effect of motivation for medication use on therapeutic alliance and medication adherence was $50 \%$, whereas that on insight and medication adherence was $41 \%$ and that on medical social support and medication adherence was $72 \%$.

Conclusion: Developing a medication motivation care model may be more effective than promoting therapeutic alliance, insight, or medical social support for promoting medication adherence. It also had greater impact on preventing relapses of community-dwelling patients with schizophrenia.

Keywords: cross-sectional study, medication adherence, disease management, motivation for medication use, schizophrenia, community-dwelling patients

\section{Introduction}

The worldwide prevalence of schizophrenia is $0.25-0.64 \% .^{1}$ In Taiwan, it is $0.5 \%$ and has increased by $1.34-2.87 \%$ in the past five years. ${ }^{2}$ Schizophrenia symptoms include delusions, hallucinations, and disorganized behavior and speech that can be stabilized by appropriate medical treatment. ${ }^{3,4}$ Deinstitutionalization and development of mental health services have resulted in an ongoing increase in the proportion of patients with schizophrenia living in the community, which is currently estimated at $75-95 \%$. Medication adherence is essential for successful psychiatric rehabilitation or recovery; however, this adherence is generally $<50 \%$ in schizophrenia and other psychotic disorders. ${ }^{5}$ Medication adherence and maintaining stable condition is vital in Taiwan and other Asian countries as aging patients
Correspondence: Wen I Liu National Taipei University of Nursing and Health Sciences, No. 365, Ming-Te Road, Peitou District, Taipei City 11219 , Taiwan Tel +886228227101 Ext. 3184

Fax +886228213233

Email wenyi@ntunhs.edu.tw 
with mental disorders who live in the community are given daily care by family members. ${ }^{2,6}$

Medication adherence has been achieved in patient-centered therapeutic alliance models, wherein healthcare providers and patients discuss treatment with mutual acceptance of an agreement with treatment. Patients can then perform medication self-management and self-maintenance behaviors. ${ }^{7,8}$ A recent systematic review found that only $47 \%$ of patients with schizophrenia adhere to medication. ${ }^{5}$ Non-adherence causes relapses and hospitalizations that have adverse effects on global function and quality of life. ${ }^{8,9}$ Recent studies have reported increased relapse rates with nonadherence in each of the first three years of treatment-from $79 \%$ in the first year to $94 \%$ in the second year. The recurrence rate was only $3 \%$ with continuing adherence to prescribed medications. ${ }^{10,11}$ Non-adherence also leads to decreased effectiveness of drug treatment, increased risk of violent behavior or suicide, decreased life satisfaction, and increased healthcare costs. ${ }^{12,13}$

An extensive review of the literature revealed that the following factors have impact on medication adherence: sex, age, marital status, education level, employment status, illness duration, number of hospitalizations, global function, symptoms, types of antipsychotic medication, drug formulation, daily dose, side effects, therapeutic alliance, insight, and medical and social support. Thus, they were included in the analysis. ${ }^{5,14-18}$ Among them, therapeutic alliance, insight, and medical social support have reliable predictive power for medication adherence, ${ }^{2,19}$ so healthcare professionals are addressing these factors by using disease management to improve medication adherence in patients with schizophrenia. However, $40 \%$ of the patients were unaware of their disease ${ }^{20}$ and $21.5 \%$ had low social support, ${ }^{21}$ indicating that disease management cannot be easily improved immediately by changing these disease management-related factors for improving medication adherence. Other valid factors such as motivation for medication use and new strategies for improving medication adherence should be explored.

Motivation is a goal-oriented idea and can trigger and affect behavior, and all activities or behaviors of individuals are caused by motivation. ${ }^{22}$ Motivation has an essential influence on task performance. The theory of planned behavior (TPB) describes three preinfluence factors for motivation: attitude toward behavior, subjective norms, and perceived behavioral control. These internal and external factors affect motivation, which in turn affects the performance $^{22}$ Based on TPB, the definition of motivation for medication use in this study is to perform medication adherence.

The motivation for medication use could be motivated by internal or external factors. For example, the patients had stated that "the medicine can't stop, I know... This medicine can make me feel better. Because I can take normal life and let me keep away from the darkness." "My mother has been taking care of me for more than 10 years. I want to continue taking medicine, don't let my mother work hard." "I am willing to continue taking medicine because my illness may be good, then I can find a work." These reasons, including internal and external factors, can promote the patient's motivation regarding medication use and improve medication adherence. Therefore, the motivation for medication use is a very important factor. ${ }^{23,24}$ related to medication adherence.

However, very little research exploring the impact of motivation for medication use on disease management factors and medication adherence is available; only one quantitative study that investigated the mediating effect of motivation for medication use in patients with schizophrenia, but it did not consider or control for the influence of multiple factors on adherence. ${ }^{25}$

\section{Objectives And Hypothesis}

The objectives of the study were as follows: (i) determine variables significantly associated with medication adherence; (ii) after controlling significant medication adherence factors (patient-, condition-, and medication-related factors), exploring the mediating effect of the motivation for medication use on the relationships between disease management-related factors (e.g., therapeutic alliance, insight, and medical social support) and medication adherence. The main hypothesis was that motivation for medication use has a mediating effect on the relationship between disease management-related factors and medication adherence.

\section{Methods}

\section{Design And Theoretical Framework}

This cross-sectional study used correlation and regression analysis to describe the influence factors on medication adherence and investigated the mediating effect of motivation for medication use on the relationship between disease management-related factors and medication adherence. In this study, after controlling for patient-, condition-, and medication-related variables, the mediating effect of motivation for medication use on the relationship between disease 
management-related factors and medication adherence was estimated. The theoretical framework is shown in Figure 1.

\section{Setting And Participants}

The study sample was conveniently selected from the outpatient departments, psychiatric day-care centers, and home care treatment populations of two psychiatric hospitals in northern and central Taiwan during 8 months from September 1, 2016, to April 30, 2017.

Patients with a primary diagnosis of schizophrenia following the DSM-5 criteria, ${ }^{26}$ aged 20-64 years, receiving at least one type of antipsychotic medication, and willing to participate and to receive treatment at one of the study centers were eligible for inclusion. Patients with comorbid organic brain disease, substance abuse, neurocognitive disorders, or intellectual disability or residents at psychiatric long-term care institutions or nursing homes were excluded. A psychiatrist referred eligible patients after they were found mentally stable and competent to participate in this study. Data collection began after informed written consent was obtained.

\section{Data Collection And Ethics Approval}

The study was conducted following the ethical principles of the declaration of Helsinki. The owners of the assessment scales permitted to the use of their instruments. The institutional review boards of the Tsaotun Psychiatric Center, Ministry of Health and Welfare (IRB no. 105026) and Tri-Service General Hospital (TSGHIRB no. 1-10505-124) approved the study.

The data collection locations for the participants of outpatient departments and psychiatric day care were in the independent, comfortable, and private scheduled rooms. The participants of home-care treatment were in their home for data collection. Interviewers of outpatient and day care did not involve the health care services of the subjects. Although interviewers of home care were their responsible home-care nurses, it is more able to reduce the resistance to collect data than strangers who do involved in the care services. The participants filled out the questionnaires by themselves, including basic data form, Glasgow Antipsychotic Side-effect Scale (GASS), WAI-s, MOS-SSS, University of Rhode Island Change Assessment (URICA), and Medication Adherence Rating Scale (MARS); then, the interviewers (home-care nurses or researchers) completed the assessor-rated questionnaires, including Global Assessment of Functioning (GAF), Brief Psychiatric Rating Scale (BPRS), and 9-item Schedule for assessment Insight in Psychosis (SIP). The total time taken for data collection was about $30 \mathrm{mins}$, and data were collected only once.

The interviewers (nine home-care nurses) had been trained to follow the research ethical principles, and strictly respected the rights of the research subjects to reduce the potential reporting biases. The assessor-rated questionnaires were used by nine nurses who were trained; they evaluated

\begin{tabular}{|l|}
\hline Patient-related \\
factors \\
-Sex \\
-Age \\
-Marital status \\
-Education level \\
-Employment status \\
\hline
\end{tabular}

Disease management related factors

-Therapeutic alliance

-Insight

-Medical social support

\section{Condition- related factors \\ - Illness duration \\ - Number of hospitalizations \\ - Global function \\ -Symptoms}

Medicationrelated factors -Type of antipsychotic -Drug formulation -Daily dose -Side effects

Figure I Theoretical framework of this study. 
the same case and discussed inconsistencies. The intraclass correlation (ICC) was above 0.80 to reach the inter-rater reliability.

Participants gave written consent after they were informed of the purpose and procedures of the study, being assured of the confidentiality and anonymity of the study data. The participants were guaranteed the right to voluntary participation and withdrawal at any time without any effect on the treatment received. If the participants wanted to interrupt the research process, interviewers did not force them to finish, and their answers did not influence their care services in the further to protect their rights. The results were known only to the team members. The professional staff of outpatient and day-care departments were not informed about the results; however, the home staff collected the data, and thus, they were aware of the data. Statistical analyses were performed anonymously.

\section{Measure Variables And Tool Control Variables}

The control variables, including patient sex, age, marital status, education level, employment status, illness duration, number of hospitalizations, global function, symptoms, type of antipsychotic, drug formulation, daily dose, and side effects were obtained from the patients' selfreport and nurse-administered assessment questionnaires.

The assessor-rated questionnaires consisted of the following three measurement tools: the Global Assessment of Functioning (GAF), Brief Psychiatric Rating Scale (BPRS), and Glasgow Antipsychotic Side-effect Scale (GASS). The single-term GAF uses a 0-100 Likert scale to measure the overall psychosocial and employment function, with higher scores indicating better functioning. ${ }^{27}$ The intraclass correlation coefficient of GAF was $0.89-0.95$, showing good reliability. The validity of GAF was significantly correlated with the Scale for the Assessment of Negative Symptoms (SANS) and Scale for the Assessment of Positive Symptoms (SAPS) that had good reliability and validity. ${ }^{28}$ The 16 -item BPRS uses a 7-point Likert scale to measure the psychiatric symptoms and psychopathology, with higher scores indicating worse psychopathology, with good reliability and validity. ${ }^{29}$ The 22-item GASS uses a 4-point Likert scale to measure the severity of the adverse effects of the antipsychotic medication, with higher scores indicating more frequent adverse events. $^{30}$ The Cronbach $\alpha$ of GASS was $0.79,{ }^{31}$ and the validity of GASS was significantly correlated with Liverpool University Neuroleptic Side Effect Rating Scale

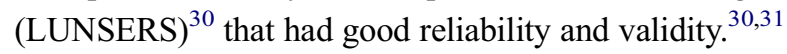

\section{Independent Variables And Mediators}

The disease management-related factors, therapeutic alliance, insight, and medical social support were independent variables. The mediator variable was motivation for medication use. These variables were obtained from the patient selfreport and nurse-administered assessment questionnaires.

The 12-item Working Alliance Inventory-Short (WAI-S) uses a 7-point Likert scale to measure therapeutic alliance, with higher scores indicating better therapeutic alliance. ${ }^{32}$ The Cronbach $\alpha$ of WAI-S was. $90,{ }^{33}$ the total variance explained was $73.4 \%,{ }^{34}$ indicating good reliability and validity. ${ }^{33,34}$ The Medical Outcome Study Social Support Survey (MOS-SSS) uses a 5-point Likert scale to measure the medical social support, with higher scores indicating better support. ${ }^{35}$ The Cronbach $\alpha$ of MOS-SSS was.97, the total variance explained was $72.7 \%$, with good reliability and validity. ${ }^{36} \mathrm{SIP}$ uses a 5-point Likert scale, with higher scores indicating poor insight. ${ }^{37}$ The Cronbach $\alpha$ of SIP was 0.92 , and the criterion-related validity of SIP was significantly correlated with Scale to assess Unawareness of Mental Disorder, with good reliability and validity. ${ }^{37}$

The 32-item URICA uses a 5-point Likert scale to measure motivation for medication use, with higher scores indicating better motivation. ${ }^{38}$ The Cronbach $\alpha$ of URICA was $0.65-0.73$, the total variance explained was $41.1 \%$, indicating good reliability and validity. ${ }^{38}$ For this study, all the Cronbach's $\alpha$ of the questionnaires were confirmed $>0.70$ $(\mathrm{GASS}=0.89 ;$ WAI-s $=0.92 ;$ MOS-SSS $=0.91 ; \mathrm{BPRS}=$ 0.76 ; $\mathrm{SIP}=0.89$; URICA $=0.92$ ) had good reliability.

\section{Dependent Variables}

The dependent variable of this study was medication adherence. Blood drug concentration and the number of calculated drugs are well-known objective measurement tools of medication adherence. Considering the high cost, time, and potential resistance of the participants toward these objective tools, a subjective measurement tool with good psychometric test was used in this study.

MARS is a valid and reliable new inventory for measuring medication adherence, consisting of ten questions developed by Thompson et al (2000). This scale ranges from 0 to 10 (as continuous variable, increased MARS scores indicated better adherence). ${ }^{39}$ A principal-components analysis revealed the following three underlying factors: medication adherence behavior (accounted for $32 \%$ of the variance); subjects' attitude to taking medication (accounted for $16 \%$ of the variance); and negative side effects and attitudes to psychotropic medication(accounted for $12 \%$ of the variance). 
These factors accounted for $59 \%$ of the total variance. Lithium levels and carer ratings of adherence were also recorded and used to verify compliance. The validity of MARS was significantly correlated with blood drug concentration $(r=0.60, p<0.05){ }^{39,40}$ The Cronbach $\alpha$ of MARS was 0.72 . We concluded that the tool had good reliability and validity with reasonable cost and time requirement. Therefore, this study did not use any other measurement tool or clinical information to repeatedly verify the patient's medication adherence. For this study, Cronbach's $\alpha$ of MARS had satisfaction reliability (MARS $=0.70$ ).

\section{Statistical Analysis}

IBM SPSS version 21.0 (IBM Corp, Armonk, NY, USA) was used to calculate the reliability (Cronbach's $\alpha$ ) of each tool in this study to ensure the reliability of the research data. Then, we used SPSS software to describe frequency distributions, percentages, and means and standard deviations (SDs) of study variables to present participant characteristics, distribution of each variable.

For descriptive statistics, the MARS scores were calculated as binary variables. In inferential statistics (correlation and mediation analysis), MARS was a continuous variable; $t$-test and one-way analysis of variance were used to compare differences of categorical variables and medication adherence. Pearson's correlation coefficient was used to describe the association between continuous variables and medication adherence to determine significant factors associated with medication adherence.

For exploring the mediating effect of the motivation for medication use, we controlled the significant factors associated with the medication adherence before using the causal steps in hierarchical regression to examine the mediating effect. ${ }^{41}$ This study had confirmed the assumptions of regression, including residual normal distribution, homoscedasticity, independence, and multicollinearity.

The causal steps hierarchical regression requires three established paths (path a, path b, path c). In path a, independent variables had a significant effect on the mediating variable. In path $b$, when both the independent and mediating variable were added, mediating variable had a significant effect on dependence variable. In path $\mathrm{c}$, the independent variables had a significant effect on the dependence variable. If the path c' regression correlation coefficient (when both independent and mediating variable were added, the independent variable affects the dependent variable) is not significant, it is termed full mediation. If the path c' regression correlation coefficient is significant, then it is called partial mediation. ${ }^{42}$
Indirect effects might be missed if only the causal steps method is used. ${ }^{43,44}$ Therefore, the significance of indirect effects $(Z>1.96)$ was calculated as described by Sobel. ${ }^{45}$

\section{Results \\ Participant Characteristics And Medication Adherence}

The response rate was $95.4 \%$, with 373 of the 391 participants included in the analysis after exclusion of eight participants with incomplete questionnaires. The majority of participants $(58.2 \%)$ were men; fewer than half had completed high school (44.5\%); the average age was 46.61 years ( $\mathrm{SD}=9.1$, range: $20-64)$; and more than two-thirds were single (70.8\%) and unemployed (76.4\%). When treated as a continuous variable, the average MARS score was $6.04(\mathrm{SD}=2.43$, range: $0-10)$.

To clearly show the status of medication adherence, the MARS score was divided into adherence and nonadherence. ${ }^{46}$ The medication adherence rate was $47.2 \%$, with 176 participants having scores $>6$. Participants receiving outpatient care had the highest adherence rate $(62 \%)$; those receiving day care had an adherence rate of $56 \%$, and those receiving home care had an adherence rate of $41 \%$.

\section{Factors Associated With Medication Adherence}

For inferential statistics, the medication adherence was calculated as a continuous variable. Medication adherence (MARS total score) was significantly correlated with the number of hospitalizations $(r=-0.19, p<0.001)$; global function ( $r=0.17, p=0.001)$; symptoms $(r=-0.18, p=0.001)$, and side effect $(r=-0.12, p=0.017)$, but the relationship was very weak. ${ }^{47}$ Therapeutic alliance $(r=0.39, p=0.001)$, medical social support $(r=0.25, p=0.001)$, insight $(r=-0.31$, $p=0.001)$ were weakly correlated with medication adherence. Motivation for medication use ( $r=0.43, p=0.001)$ was moderate correlated with medication adherence. ${ }^{47}$

Sex, age, marital status, education level, employment status, duration of illness, type of antipsychotic medication, drug formulation, and daily dose frequency were not significantly associated with medication adherence $(p>0.05)$. The relationships between various factors and medication adherence are shown in Table 1.

\section{Mediating Effects}

Hierarchical regression assumes a residual normal distribution, homoscedasticity, and independence (Durbin-Watson 
Table I Distribution Of Various Factors And Relationships With Medication Adherence

\begin{tabular}{|c|c|c|c|c|c|}
\hline \multirow[t]{2}{*}{ Factors } & \multicolumn{2}{|c|}{ Data Distribution } & \multicolumn{3}{|c|}{ Relationship With Adherence } \\
\hline & $\mathbf{N}(\%)$ & $M(S D)$ & Mean (SD) & $t^{\mathrm{a}} / \mathrm{r}^{\mathrm{b}} / F^{\mathrm{c}}$ & $p$ \\
\hline $\begin{array}{l}\text { Gender } \\
\text { Male } \\
\text { Female }\end{array}$ & $\begin{array}{l}217(58.2) \\
156(4 \mid .8)\end{array}$ & & $\begin{array}{l}6.18(2.38) \\
5.85(2.50)\end{array}$ & $1.32^{\mathrm{a}}$ & 0.186 \\
\hline Age & & $46.61(9.09)$ & & $0.07^{\mathrm{b}}$ & 0.160 \\
\hline $\begin{array}{l}\text { Marital status } \\
\text { Single } \\
\text { Married } \\
\text { Divorced/widower }\end{array}$ & $\begin{array}{l}264(70.8) \\
58(15.5) \\
51(13.7) \\
51(13.7)\end{array}$ & & $\begin{array}{l}6.00(2.40) \\
5.76(2.48) \\
6.57(2.52)\end{array}$ & $1.62^{c}$ & 0.199 \\
\hline $\begin{array}{l}\text { Education level } \\
\text { Middle school or below } \\
\text { Senior high school } \\
\text { College and above }\end{array}$ & $\begin{array}{l}132(35.4) \\
166(44.5) \\
75(20.1)\end{array}$ & & $\begin{array}{l}5.82(2.40) \\
6.23(2.47) \\
6.05(2.42)\end{array}$ & $1.06^{c}$ & 0.347 \\
\hline $\begin{array}{l}\text { Employment status } \\
\text { Unemployment } \\
\text { Employed part-time } \\
\text { Employed full time }\end{array}$ & $\begin{array}{l}285(76.4) \\
49(13.1) \\
39(10.5)\end{array}$ & & $\begin{array}{l}6.03(2.40) \\
6.06(2.63) \\
6.13(2.46)\end{array}$ & $0.03^{c}$ & 0.970 \\
\hline $\begin{array}{l}\text { Illness duration } \\
\text { Number of hospitalizations } \\
\text { Global function } \\
\text { Symptoms }\end{array}$ & & $\begin{array}{l}22.42(9.15) \\
5.44(6.20) \\
69.54(15.28) \\
12.29(7.25)\end{array}$ & & $\begin{array}{l}0.06^{\mathrm{b}} \\
-0.19^{\mathrm{b}} \\
0.17^{\mathrm{b}} \\
-0.18^{\mathrm{b}}\end{array}$ & $\begin{array}{l}0.241 \\
<0.00 I^{* * *} \\
0.00 I^{* *} \\
0.001^{* *}\end{array}$ \\
\hline $\begin{array}{l}\text { Type of antipsychotic } \\
\text { Typical } \\
\text { Untypical } \\
\text { Mix }\end{array}$ & $\begin{array}{l}66(17.7) \\
276(74.0) \\
31(8.3)\end{array}$ & & $\begin{array}{l}5.92(2.53) \\
6.09(2.4 I) \\
5.84(2.53)\end{array}$ & $0.25^{c}$ & 0.781 \\
\hline $\begin{array}{l}\text { Drug formulation } \\
\text { Oral } \\
\text { IM } \\
\text { Mix }\end{array}$ & $\begin{array}{l}297(79.6) \\
33(8.9) \\
43(11.5)\end{array}$ & & $\begin{array}{l}6.13(2.44) \\
5.24(2.40) \\
6.07(2.40)\end{array}$ & $1.98^{\mathrm{c}}$ & 0.140 \\
\hline $\begin{array}{l}\text { Daily dose } \\
\text { Side effects } \\
\text { Therapeutic alliance } \\
\text { Insight } \\
\text { Medical social support } \\
\text { Motivation for medication use }\end{array}$ & & $\begin{array}{l}1.45(0.84) \\
11.99(10.38) \\
60.11(14.24) \\
19.98(5.52) \\
17.94(6.09) \\
8.23(2.19)\end{array}$ & & $\begin{array}{l}0.07^{\mathrm{b}} \\
-0.12^{\mathrm{b}} \\
0.39^{\mathrm{b}} \\
-0.31^{\mathrm{b}} \\
0.25^{\mathrm{b}} \\
0.43^{\mathrm{b}}\end{array}$ & $\begin{array}{l}0.151 \\
0.017^{*} \\
<0.001^{* * *} \\
<0.001^{* * *} \\
<0.001^{* * *} \\
<0.001^{* * *}\end{array}$ \\
\hline $\begin{array}{l}\text { Medication adherence } \\
\text { Adherence } \\
\text { Nonadherence }\end{array}$ & $\begin{array}{l}176(47.2) \\
197(52.8)\end{array}$ & $6.01(2.43)$ & & $\begin{array}{l}- \\
-\end{array}$ & $\begin{array}{l}- \\
-\end{array}$ \\
\hline
\end{tabular}

Notes: ${ }^{\mathrm{a}}$-test; ${ }^{\mathrm{b}}$ Pearson's correlation $(\boldsymbol{R})$; ${ }^{\mathrm{c}}$ ANOVA $(F) ;{ }^{*} P<0.05 . * * P<0.01 .{ }^{*} * * P<0.001$.

test $=1.94-2.00)$ but not multicollinearity (variance inflation factor $=1.10-3.12 ;<10)$. The four paths of Baron and Kenny ${ }^{41}$ illustrate the mediation effects of the motivation for medication use on disease management (therapeutic alliance, insight, and medical social support) and medication adherence. The four paths of the mediation model are shown in Figure 2. The mediating effects of the total, direct, and indirect influencers are shown in Table 2. 


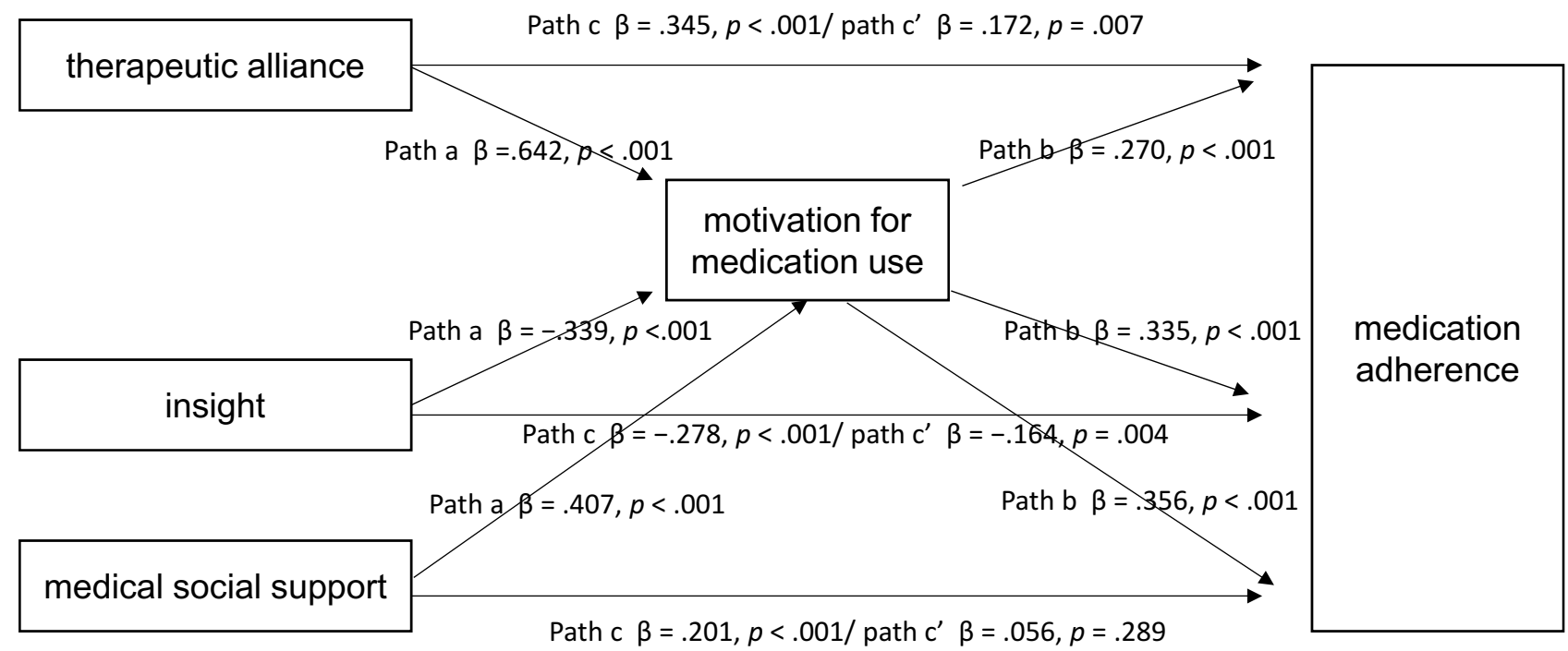

Figure 2 Mediating effects of motivation for medication use on disease management related factors and medication adherence.

Motivation On Therapeutic Alliance And Medication Adherence

Path a $(\beta=0.642, p<0.001)$, path $\mathrm{b}(\beta=0.270, p<0.001)$, path $\mathrm{c}(\beta=0.345, p<0.001)$, and path $\mathrm{c}^{\prime}(\beta=0.172, p=0.007)$ also had a significant effect. The Sobel test for indirect effects of mediation was significant $(\mathrm{Z}=4.21, p<0.001)$. Therefore, the motivation for medication use had a partial mediating effect on therapeutic alliance and medication adherence. The direct effect of therapeutic alliance on medication adherence was 0.172 , and the indirect effect through motivation for medication use was 0.173 , the mediating effect was $50 \%$.

\section{Motivation On Insight And Medication Adherence}

Path a $(\beta=-0.339, p<0.001)$, path $\mathrm{b}(\beta=0.335, p<0.001)$, path c $(\beta=-0.278, p<0.001)$, and path c' $(\beta=-0.164$, $p=0.004)$ also had a significant effect. The Sobel test for indirect effects of mediation was significant $(\mathrm{Z}=-4.43$, $p<0.001)$. Therefore, the motivation for medication use had a partial mediating effect on insight and medication adherence. The direct effect of insight on medication adherence was -0.164 , and the indirect effect through motivation for medication use was -0.114 ; the mediating effect was $41 \%$.

\section{Motivation On Medical Social Support And Medication Adherence}

Path a $(\beta=0.407, p<0.001)$, path $\mathrm{b}(\beta=0.356, p<0.001)$, path c $(\beta=0.201, p<0.001)$ had a significant effect. The Sobel test for indirect effects of mediation was significant $(\mathrm{Z}=5.24, p<0.001)$. But, path c' was not significant $(\beta=$ $0.056, p=0.289)$. Therefore, the motivation for medication use had a full mediating effect on medical social support and medication adherence. The direct effect of medical social support on medication adherence was 0.056 , and the indirect effect by motivation for medication use was 0.145 ; the mediating effect was $72 \%$.

\section{Discussion}

Using the scoring system described by Abrar et al, ${ }^{46}$ medication adherence was $42 \%$ in community-dwelling patients

Table 2 Summary Of The Mediating Effects Of Motivation For Medication Use On Disease Management Related Factors And Medication Adherence

\begin{tabular}{|l|l|l|l|l|l|l|l|}
\hline \multirow{2}{*}{ Predictors } & \multicolumn{2}{l|}{ Total Effect } & \multicolumn{2}{l|}{ Direct Effect } & \multicolumn{2}{l|}{ Indirect Effect } \\
\cline { 2 - 8 } & $\boldsymbol{\beta}$ & $\boldsymbol{\beta}$ & $\boldsymbol{\beta}$ & $\boldsymbol{\beta}$ & $\boldsymbol{\beta}$ & $\boldsymbol{p}$ & Proportion Mediated \\
\hline Therapeutic alliance & 0.345 & $<0.001$ & 0.172 & 0.007 & 0.173 & $<0.001$ & $50 \%$ \\
Insight & -0.278 & $<0.001$ & -0.164 & 0.004 & -0.114 & $<0.001$ & $41 \%$ \\
Medical social support & 0.201 & $<0.001$ & 0.056 & 0.289 & 0.145 & $<0.001$ & $72 \%$ \\
\hline
\end{tabular}

Note: Proportion mediated $(\%)=$ indirect effect/total effect. 
with schizophrenia, indicating that more than half of the study participants were nonadherent. Medication adherence rate was the highest in outpatient care patients and the lowest in those with home care. Medication adherence was associated with functional status and cognitive level. ${ }^{2,48}$

After controlling for patient characteristics, illness condition, and medication prescription and dosage, motivation for medication use was a mediator of the contribution or influence of disease management to medication adherence. This result is consistent with TPB and research described by Rungruangsiripan et $\mathrm{al}^{25}$ and supports motivation for medication use as a critical mediator of medication adherence. The transtheoretical model describes change as a progression through a series of stages depending on the motivation to change, and which cannot achieve the goal in a short period. ${ }^{49}$

The factors related to the mediating effects of the motivation for medication use on disease management and medication adherence in community-dwelling patients with schizophrenia are not well understood. Recent studies have investigated motivation-related factors in diabetes, ${ }^{50,51}$ epilepsy, ${ }^{52}$ and hypertension, ${ }^{53}$ these studies also supported the motivation for medication use is an essential mediator to medication adherence. Rungruangsiripan et $\mathrm{al}^{25}$ reported that a low level of motivation affected medication adherence and mental health professionals in Taiwan and other developed countries had described disease management strategies and interventions that promote medication adherence. ${ }^{54,55}$ This study found that the influence of therapeutic alliance, insight, and medical social support on patient medication adherence was relatively smaller than that of the motivation for medication use. Mental health professionals may not fully appreciate the effect of enhancing patient motivation for medication use has on medication adherence. Published data on the mediating effects of motivation for medication use on medication adherence in patients with schizophrenia in Taiwan and other countries was inadequate. ${ }^{56-60}$

The study results indicate that interventions to promote medication adherence, such as motivational interviews, ${ }^{56,60}$ may confer more significant benefits on increased medication adherence in schizophrenia, than other psychosocial interventions emphasizing therapeutic relationships, increasing insight, or providing medical social support. Motivation-based programs can help a majority of community-dwelling patients with schizophrenia who are not adherent to their antipsychotic regimen to control their psychotic symptoms, thus reducing relapse occurrence and the medical burden in society.

\section{Strengths And Limitations}

This may be the first study to focusing on the mediating effect of motivation for medication use as a link between disease management related factors and medication adherence in schizophrenia after controlling for multiple dimensions. The study included a large patient sample, and the findings can be generalized to the Taiwan general population.

The main variable in this study was only measured by MARS. Although MARS is subjective measurement tools and may be overestimate medication adherence, it had economically efficient, noninvasive procedure, suitable for clinical care, significantly related to objective blood drug concentration, ${ }^{39,61}$ and the meta-analysis indicated self-filling scale was a good estimation tool for medication adherence. $^{62}$ Therefore, we chose MARS as the measurement tool. This study was a cross-sectional, descriptive design lacking causal inference. A longitudinal study would be able to evaluate the causal relationships of variables. The explained variance of the URICA inventory is less than half, but it is a better analytical tool than the current one. We recommend developing more condition-specific motivation scales. We included as many variables that affect medication adherence as possible but may not have included all that was active. Future investigations of the relationships of medication adherence and motivation might include additional variables. It is also essential to develop motivational interviewing for community-dwelling patients with mental disorders and then use carefully designed randomized controlled trials to investigate the effectiveness of motivational interviewing on improving disease management and medication adherence.

\section{Conclusion}

Nearly half of the patients with schizophrenia were nonadherent to medication. The number of hospitalizations, symptoms, medication side effects, global function, therapeutic alliance, insight, medical social support, and motivation for medication use was associated with medication adherence. Disease management-related factors (therapeutic alliance, insight, and medical social support) significantly influenced medication adherence. If disease management factors are difficult to change, then the motivation for medication use is an essential mediator of medication adherence.

\section{Implications For Practice}

The findings support the casual relationship of motivation for medication use as a mediator of the disease management strategies used in mental healthcare services and the achieved 
level of medication adherence. Motivational interventions can enhance the effectiveness of current schizophrenia management practiced in community-based rehabilitation, involving therapeutic alliance, inducing insight, and medical social support. The study results can inform the design and evaluation of motivation-based adherence therapy to promote or enhance medication adherence in community-dwelling psychosis patients with poor medication adherence to reduce relapse and readmission.

\section{Acknowledgments}

The authors are grateful to the psychiatric center to contribute to the research and also the Taiwanese psychiatric nurses for their assistance in the recruitment of participants and data collection. The Ministry of Health and Welfare provided the funding required for this project (Grant No. 10647). The views and opinions expressed in this manuscript are the authors' own.

\section{Disclosure}

The authors report no conflicts of interest in this work.

\section{References}

1. National Institute of Mental Health. Mental health information. 2018. Available from: https://www.nimh.nih.gov/health/statistics/schizophre nia.shtml. Accessed March 9, 2019.

2. Ministry of Health and Welfare. The numbers of individuals with disabilities. 2016. Available from: http://www.mohw.gov.tw/cht/DOS/ Statistic.aspx?f_list_no=312\&fod_list_no $=4198$. Accessed April 10, 2017.

3. Leucht S, Corves C, Arbter D, Engel RR, Li C, Davis JM. Secondgeneration versus first- generation antipsychotic drugs for schizophrenia: a meta-analysis. Lancet. 2009;373(9657):31-41. doi:10.10 16/S0140-6736(08)61764-X

4. Miller BJ, Bodenheimer C, Crittenden K. Second-generation antipsychotic discontinuation in first episode psychosis: an updated review. Clin Psychopharmacol Neurosci. 2011;9(2):45-53. doi:10.9758/ cpn.2011.9.2.45

5. Sendt KV, Tracy DK, Bhattacharyya S. A systematic review of factors influencing adherence to antipsychotic medication in schizophreniaspectrum disorders. Psychiatry Res. 2015;225(1):14-30. doi:10.1016/j. psychres.2014.11.002

6. Rong JR, Yang TY, Laiu WI, Hung TM, Hung FF, Shiau SJ. Exploring essential competences and credentialing model of community psychiatric mental health nursing. J Psychiatr Ment Health Nurs. 2008;3(2): $1-9$.

7. Huang JY, Chen HM. Concept analysis of medication adherence in patients with chronic disease. $J$ Nurs. 2014;61(3):112-118. doi:10.62 24/JN.61.3.112.

8. World Health Organization. Adherence to long-term therapies: policy for action. 2001. Available from: http://www.who.int/chp/knowledge/ publications/adherencerep.pdf. Accessed April 10, 2017.

9. Xiao J, Mi W, Li L, Shi Y, Zhang H. High relapse rate and poor medication adherence in the Chinese population with schizophrenia: results from an observational survey in the people's republic of China. Neuropsychiatr Dis Treat. 2015;11:1161-1167. doi:10.2147/NDT. S72367
10. Emsley R, Oosthuizen PP, Koen L, Niehaus DJ, Martinez G. Symptom recurrence following intermittent treatment in first-episode schizophrenia successfully treated for two years: a 3-year open-label clinical study. J Clin Psychiatry. 2012;73(4):541-547. doi:10.4088/ JCP. $11 \mathrm{~m} 07138$

11. Zipursky RB, Menezes NM, Streiner DL. Risk of symptom recurrence with medication dis- continuation in first-episode psychosis: a systematic review. Schizophr Res. 2014;152:408-414. doi:10.1016/j. schres.2013.08.001

12. Dilla T, Ciudad A, Alvarez M. Systematic review of the economic aspects of nonadherence to antipsychotic medication in patients with schizophrenia. Patient Prefer Adherence. 2013;7:275-284. doi:10.21 47/PPA.S41609

13. Lindenmayer JP, Liu-Seifert H, Kulkarni PM, et al. Medication nonadherence and treatment outcome in patients with schizophrenia or schizoaffective disorder with a suboptimal prior response. J Clin Psychiatry. 2009;70(7):990-996. doi:10.4088/JCP.08m04221

14. Leclerc E, Noto C, Bressan RA, Brietzke E. Determinants of adherence to treatment in first-episode psychosis: a comprehensive review. Rev Bras Psiquiatr. 2015;37(2):168-176. doi:10.1590/1516-44462014-1539

15. Novick D, Montgomery W, Treuer T, Aguado J, Kraemer S, Haro JM. Relationship of insight with medication adherence and the impact on outcomes in patients with schizophrenia and bipolar disorder: results from a 1-year European outpatient observational study. BMC Psychiatry. 2015;15(1):1-8. doi:10.1186/s12888-015-0560-4

16. Shuler KM. Approaches to improve adherence to pharmacotherapy in patients with schizo phrenia. Patient Prefer Adherence. 2014;8:701714. doi:10.2147/PPA.S59371

17. Higashi K, Medic G, Littlewood KJ, Diez T, Granstrom O, De Hert M. Medication adherence in schizophrenia: factors influencing adherence and consequences of nonadherence, a systematic literature review. Ther Adv Psychopharmacol. 2013;3(4):200-218. doi:10.11 77/2045125312474019

18. Eticha T, Teklu A, Ali D, Solomon G, Alemayehu A. Factors associated with medication adherence among patients with schizophrenia in Mekelle, Northern Ethiopia. PLoS One. 2015;10(3):1-11. doi:10.1371/journal.pone. 0120560

19. Velligan DI, Sajatovic M, Hatch A, Kramata P, Docherty JP. Why do psychiatric patients stop antipsychotic medication? a systematic review of reasons for nonadherence to medication in patients with severe mental illness. Patient Prefer Adherence. 2017;11:449-468. doi:10.2147/PPA.S124658

20. Ramachandran AS, Ramanathan R, Praharaj SK, Kanradi H, Sharma PSVN. A cross- sectional, comparative study of insight in schizophrenia and bipolar patients in remission. Indian J Psychol Med. 2016;38(3):207-212. doi:10.4103/0253-7176

21. Mekonnen M, Boru B, Yohannis Z, Abebaw D, Birhanu A. Level of perceived social support and associated factors among people with schizophrenia attending outpatient department at amanuel mental specialized hospital. J Psychopharmacol. 2019;22:1-7. doi:10.4172/ 2378-5756.1000461

22. National Academy for Educational Reasearch. Theories of motivation. 2000. Available from: http://terms.naer.edu.tw/detail/1309154/. Accessed April 10, 2017.

23. Ajzen I. The theory of planned behavior. Organ Behav Hum Decis Process. 1991;50:179-211. doi:10.1016/0749-5978(91)90020-T

24. Chang YT, Tao SG, Lu CL. Qualitative inquiry into motivators for maintaining medication adherence among Taiwanese with schizophrenia. Int J Ment Health Nurs. 2013;22(3):272-278. doi:10.1111/ j.1447-0349.2012.00864.x

25. Rungruangsiripan M, Sitthimongkol Y, Maneesriwongul W, Talley S, Vorapongsathorn T. Mediating role of illness representation among social support, therapeutic alliance, the experience of medication side effects, and medication adherence in persons with schizophrenia. Arch Psychiatr Nurs. 2011;25(4):269-283. doi:10.1016/j.apnu.2010.09.002 
26. American Psychiatric Association. Diagnostic and Statistical Manual of Mental Disorders: DSM-5. Washington: Am J Psychiatry; 2013.

27. American Psychiatric Association. Diagnostic and Statistical Manual of Mental Disorders: DSM-IV-TR. Washington: Am J Psychiatry; 2000.

28. Startup M, Jackson MC, Bendix S. The concurrent validity of the Global Assessment of Functioning (GAF). $\mathrm{Br} J$ Clin Psychol. 2002;41(4):417-422. doi:10.1348/014466502760387533

29. Chang TJ, Hwu HG, Wei FW. The inter-rater reliability of brief psychiatric rating scale (BPRS). Chin Soc Neurol Psychiatry Bull. 1986;12(1):29-36.

30. Waddell L, Taylor M. A new self-rating scale for detecting atypical or second-generation antipsychotic side effects. J Psychopharmacol. 2008;22(3):238-243. doi:10.1177/0269881107087976

31. Nystazaki M, Tsapakis E, Hadjulis M, Alevizopoulos G. Validation of the Glasgow Antipsychotic Side-Effect Scale (GASS) in Greece. $J$ Child Psychol Psychiatry. 2014;1(4):1-6. doi:10.15406/jpcpy.2014. 01.00024

32. Tracey TJ, Kokotovic AM. Factor structure of the working alliance inventory. J Consult Clin Psychol. 1989;1(3):207-210. doi:10.1037/ 1040-3590.1.3.207

33. Munder T, Wilmers F, Leonhart R, Linster HW, Barth J. Working Alliance Inventory-Short Revised (WAI-SR): psychometric properties in outpatients and inpatients. Clin Psychol Psychother. 2010;17 (3):231-239. doi:10.1002/cpp.658

34. Andrusyna TP, Tang TZ, DeRubeis RJ, Luborsky L. The factor structure of the Working Alliance Inventory in cognitive-behavioral therapy. J Psychother Pract Res. 2001;10(3):173-178.

35. Yu DS, Lee DT, Woo J. Psychometric testing of the Chinese version of the Medical Outcomes Study Social Support survey (MOS-SSSC). Res Nurs Health. 2004;27(2):135-143. doi:10.1002/nur.20008

36. Alonso FA, Montes MA, Menendez VC, Pereira MG. Cultural adaptation and validation of the medical outcomes study social support survey questionnaire (MOS-SSS). Acta Med Port. 2006;20(6):525534.

37. Yen CF, Yeh ML, Chong MY, Chung HH, Chen CS. A multidimensional assessment of insights in schizophrenic patients. Kaohsiung $J$ Med Sci. 2001;17(5):253-260.

38. Chan SC, Chan CC, Siu AM, Poon PK. Stage of change in selfmanagement of chronic diseases: psychometric properties of the Chinese version of the University of Rhode Island Change Assessment (C-URICA) Scale. Rehabil Psychol. 2007;52(1):103112. doi:10.1037/0090-5550.52.1.103

39. Thompson K, Kulkarni J, Sergejew AA. Reliability and validity of a new Medication Adherence Rating Scale (MARS) for the psychoses. Schizophr Res. 2000;42(3):241-247. doi:10.1016/S0920-9964(99) 00130-9

40. Kao YC, Liu YP. Compliance and schizophrenia: the predictive potential of insight into illness, symptoms, and side effects. Compr Psychiatry. 2010;51(6):557-565. doi:10.1016/j.comppsych.2010.03. 007

41. Baron RM, Kenny DA. The moderator-mediator variable distinction in social psychological research: conceptual, strategic, and statistical considerations. J Pers Soc Psychol. 1986;51(6):1173-1182. doi:10.10 37/0022-3514.51.6.1173

42. Hayes AF. Introduction to Mediation, Moderation, and Conditional Process Analysis: A Regression-Based Approach. New York: Guilford Press; 2013.

43. MacKinnon DP, Lockwood CM, Hoffman JM, West SG, Sheets V. A comparison of methods to test mediation and other intervening variable effects. Psychol Methods. 2002;7(1):83-104. doi:10.1037/1082989X.7.1.83

44. Preacher KJ, Hayes AF. SPSS and SAS procedures for estimating indirect effects in simple mediation models. Behav Res Methods Instrum Comput. 2004;36(4):717-731. doi:10.3758/BF03206553
45. Sobel ME. Asymptotic confidence intervals for indirect effects in structural equation models. Sociol Methodol. 1982;13:290-312. doi:10.2307/ 270723

46. Abrar S, Shoka A, Arain N, Widuch-Mert C. Landing on the MARS! BJMP. 2012;5(3):9-14.

47. British Medical Journal. Correlation and regression. 2011. Available from: https://www.bmj.com/about-bmj/resources-readers/publications/ statistics-square-one/11-correlation-and-regression. Accessed October 6, 2018.

48. Hill M, Crumlish N, Whitty P, et al. Nonadherence to medication four years after the first episode of psychosis and associated risk factors. Psychiatric Serv. 2010;61(2):189-192. doi:10.1176/ps.2010.61.2.189

49. Prochaska JO, Redding CA, Evers KE. The transtheoretical model and stages of change. In: Glanz K, Barbara KR, Viswanath K, editors. Health Behavior: Theory, Research, and Practice. San Francisco: Jossey-Bass A Wiley Brand; 2015:125-148.

50. Fai EK, Anderson C, Ferreros V. Role of attitudes and intentions in predicting adherence to oral diabetes medications. Endocr Connect. 2017;6(2):63-70. doi:10.1530/EC-16-0093

51. Wu P, Liu N. Association between patients' beliefs and oral antidiabetic medication adherence in a Chinese type 2 diabetic population. Patient Prefer Adherence. 2016;10:1161-1167. doi:10.2147/PPA. S 105600

52. Lin CY, Updegraff JA, Pakpour AH. The relationship between the theory of planned behavior and medication adherence in patients with epilepsy. Epilepsy Behav. 2016;61:231-236. doi:10.1016/j.yebeh.20 16.05.030

53. Ho CP, Lee TJF. An evaluation of medication adherence in hypertensive patients using the theory of planned behavior. Value Health. 2014;17(7):763. doi:10.1016/j.jval.2014.08.270

54. Jeng KS, Huang HK, Lee CF, Shao WC, Chang YF. The effect of a project to enhance drug compliance of psychiatric patients who live in remote mountainous areas. $J$ Med Health. 2014;3(1):77-78.

55. Lin HH, Kuo YP, Lin ECL, Chen PS, Chen KC. A pilot study of the effect of an illness management group on patients with schizophrenia living in the community. $J$ Nurs Healthcare Res. 2014;10(1):15-22.

56. Chien WT, Mui J, Gray R, Cheung E. Adherence therapy versus routine psychiatric care for people with schizophrenia spectrum disorders: a randomized controlled trial. BMC Psychiatry. 2016;16(1):114. doi:10.1186/s12888-016-0744-6

57. Cook PF, Emiliozzi S, Waters C, El DH. Effects of telephone counseling on antipsychotic adherence and emergency department utilization. Am J Manag Care. 2008;14(12):841-846.

58. Schulz M, Gray R, Spiekermann A, Abderhalden C, Behrens J, Driessen M. Adherence therapy following an acute episode of schizophrenia: a multi-center randomized controlled trial. Schizophr Res. 2013;146(1):59-63. doi:10.1016/j.schres.2013.01.028

59. Staring A, Van der Gaag M, Koopmans G, et al. Treatment adherence therapy in people with psychotic disorders: randomized controlled trial. Br J Psychiatry. 2010;197(6):448-455. doi:10.1192/bjp.bp.110. 077289

60. Chien WT, Mui JH, Cheung EF, Gray R. Effects of motivational interviewing-based adherence therapy for schizophrenia spectrum disorders: a randomized controlled trial. Trials. 2015;16(1):1-14. doi:10.1186/s13063-015-0785-z

61. Stirratt MJ, Dunbar-Jacob J, Crane HM, et al. Self-report measures of medication adherence behavior: recommendations on optimal use. Transl Behav Med. 2015;5(4):470-482. doi:10.1007/s13142-0150315-2

62. Shi L, Liu J, Fonseca V, Walker P, Kalsekar A, Pawaskar M. Correlation between adherence rates measured by MEMS and selfreported questionnaires: a meta-analysis. Health Qual Life Outcomes. 2010;8(1):1-7. doi:10.1186/1477-7525-8-99 


\section{Publish your work in this journal}

Patient Preference and Adherence is an international, peer-reviewed, open access journal that focusing on the growing importance of patient preference and adherence throughout the therapeutic continuum. Patient satisfaction, acceptability, quality of life, compliance, persistence and their role in developing new therapeutic modalities and compounds to optimize clinical outcomes for existing disease

states are major areas of interest for the journal. This journal has been accepted for indexing on PubMed Central. The manuscript management system is completely online and includes a very quick and fair peer-review system, which is all easy to use. Visit http:// www.dovepress.com/testimonials.php to read real quotes from published authors. 